\title{
MICROSCOPIC STUDY OF THE CONCRETE / GEOPOLYMER COATING INTERFACE
}

\author{
\#IVANA PERNÁ, TOMÁŠ HANZLÍČEK, MARGIT ŽALOUDKOVÁ \\ Institute of Rock Structure and Mechanics, Czech Academy of Sciences, \\ V Holešovičkách 41, 18209 Prague 8, Czech Republic \\ "E-mail: perna@irsm.cas.cz
}

Submitted August 12, 2019; accepted September 25, 2019

\begin{abstract}
Keywords: Geopolymers, Concrete, Interface, Optical microscopy, Scan electron microscopy (SEM)
This paper presents an experimental study at microscopic level of the interface between geopolymer coating and concrete. Seven varieties of prepared geopolymer-based materials (GbM) have been applied to industrially prepared concrete bodies. The differences in the composition of the layers as well as in the application type (dry/wet surface) can cause ion migration from the viscose GbM to the solid concrete and reversely from the concrete to the formatted netting of the hardened geopolymer. The interlayer between the geopolymer coating layers and the hardened concrete has been investigated by two microscopic methods: optical and scanning electronic microscope equipped with SEM/EDAX analyses. The results have shown that the coating layers considerably reduce calcium ion penetration into the GbM chained structures.
\end{abstract}

\section{INTRODUCTION}

The protection of the concrete surface against negative environmental conditions has been the focus of many laboratories all over the world in the last years [1-4]. The long exposure to environmental conditions $\left(\mathrm{NO}_{x}, \mathrm{SO}_{3}^{2-}, \mathrm{CO}_{2}\right.$ and $\left.\mathrm{Cl}^{-}\right)$together with temperature changes and humidity cause slow but constant degradation of concrete [5-6]. Precipitation, evaporation and water penetration into concrete pores attack, along with the gasses, the superficial calcium hydroxide $\left(\mathrm{Ca}(\mathrm{OH})_{2}\right)$. In marine environment, there is also a danger of chloride diffusion or penetration causing concrete degradation [4]. The surface of concrete constructions is gradually damaged by fissures, cracks and sometimes even the breaking off of entire pieces of concrete.

For this reason, the improvement of the concrete surface by layers formed by various types of geopolymers using clay-based materials has been searched [7-11] Some experiments have been aimed at forming alkaliactivated coating from fly ash [12-14]. Surface coatings utilizing geopolymer-based materials (GbM) offer a new, quick and safe option for the repair of damaged concrete as verified by a previous experiment [11]. One of the advantages of geopolymer materials is the possibility of layering a fresh geopolymer material on the old and hard one, with both layers being perfectly joined $[11,15]$.

The study discusses the interaction phases of the two different types of material. The concrete based on $\mathrm{PC}$ is formed by calcium silicate hydrate $(\mathrm{C}-\mathrm{S}-\mathrm{H})$ gel, whereas geopolymer is formed by the $3 \mathrm{D}$ netting of aluminum and silicon ions joint by oxygen. This paper describes the preparation of geopolymer-based coating layers to be applied onto the already hardened concrete samples.

The differences in the properties of the materials as well as the application type can cause ion migration from the viscous GbM to the solid concrete and reversely from the concrete to the formatted netting of the condensed and hardened state of the geopolymer. The interface between the coating layers of GbM and the hardened concrete as well as the potential migration of ions have been investigated by scan electron microscopy (SEM).

\section{Geopolymer background}

Geopolymers are well-known materials formed by a reaction of an alumino-silicate precursor (metakaolin, blast-furnace slag, fly ash, etc.) with an alkaline activator based on a solution of sodium, potassium or calcium silicates $[16,17]$. The resulting solid matter is an amorphous three-dimensional inorganic net comprised of aluminum and silicon tetrahedrons joined by bridging oxygen ions $[18,19]$. Since the 1970s, when geopolymer materials were first investigated by $\mathrm{J}$. Davidovits [18], there has been a great boom in this field of science and many laboratories have focused on geopolymers from different viewpoints, e.g. synthesis, possible source materials of precursors or fillers, the resulting material properties, etc. [20-22]. The main advantage of geopolymer material is its adaptability to different user requirements, e.g. color, setting time, 
porosity, structure and properties [11, 23, 24]. All of these qualities depend on a suitable choice of additives and fillers and their content. Previous works have shown various compositions of geopolymers and the possibility to modify them based on the different types of materials used $[25,26]$. A common type of a valuable additive is blast-furnace slag $[7-9,11,23,27]$. The type and quantity of the chosen filler are responsible for the surface hardness, shrinkage and bulk changes in general. Moreover, the heat resistance of geopolymers makes it possible to increase the resistance of concrete structures at high temperatures.

\section{EXPERIMENTAL}

\section{Sample preparation}

The geopolymer material was prepared by the following procedure: The thermally activated clay material L05 $\left(750{ }^{\circ} \mathrm{C}, 4\right.$ hours) was mixed with a potassium alkaline solution (molar rates of the geopolymer mixture: $\mathrm{SiO}_{2} / \mathrm{Al}_{2} \mathrm{O}_{3}=2.96 ; \mathrm{K}_{2} \mathrm{O} / \mathrm{Al}_{2} \mathrm{O}_{3}=0.73 ; \mathrm{H}_{2} \mathrm{O} / \mathrm{K}_{2} \mathrm{O}=15.53$ ) by an overhead stirrer (at 800 revolutions per minute) for 20 minutes and then, after the addition of selected substances (see Table 1), for another 5 minutes.

Solid concrete samples comprised fragments of industrially prepared window parapets (the company Liebscher s.r.o., Czech Republic) made from the concrete M-250 (usually used for casting boards and platforms) and mixed with a corresponding addition of three

Table 1. Experiment summary.

\begin{tabular}{|c|c|c|c|}
\hline $\begin{array}{c}\text { Sample } \\
\text { label }\end{array}$ & Additives / fillers & $\begin{array}{c}\text { Content } \\
(\%)\end{array}$ & $\begin{array}{c}\text { Application } \\
\text { to a dry/wet } \\
\text { surface }\end{array}$ \\
\hline 1 & - & - & dry \\
\hline $1 \mathrm{M}$ & - & - & wet \\
\hline 2 & blast-furnace slag & 41 & dry \\
\hline $2 \mathrm{M}$ & blast-furnace slag & 41 & wet \\
\hline 3 & micro-milled quartz sand & 75 & dry \\
\hline $3 \mathrm{M}$ & micro-milled quartz sand & 75 & wet \\
\hline 4 & shale & 67 & dry \\
\hline $4 \mathrm{M}$ & shale & 67 & wet \\
\hline 5 & quartz sand & 86 & dry \\
\hline $5 \mathrm{M}$ & quartz sand & 86 & wet \\
\hline \multirow{2}{*}{6} & micro-milled quartz sand & 40 & \multirow{2}{*}{ dry } \\
\hline & quartz sand & 40 & \\
\hline \multirow{2}{*}{$6 \mathrm{M}$} & micro-milled quartz sand & 40 & \multirow{2}{*}{ wet } \\
\hline & quartz sand & 40 & \\
\hline \multirow{2}{*}{7} & micro-milled quartz sand & 19 & \multirow{2}{*}{ dry } \\
\hline & blast-furnace slag & 54 & \\
\hline \multirow{2}{*}{$7 \mathrm{M}$} & micro-milled quartz sand & 19 & \multirow{2}{*}{ wet } \\
\hline & blast-furnace slag & 54 & \\
\hline
\end{tabular}

fractions of sand, one of which was gravel sized. These samples had two different concrete surfaces - the facial one was smooth, prepared by extremely fine sand, while the opposite side contained the common distribution of quartz sand grains. The surfaces of concrete samples were slightly brushed to clean off the powder produced by cutting the samples to sizes acceptable under laboratory conditions. Each application of the GbM was performed in two modes:

- on a dry surface;

- on a surface wetted by dousing just before geopolymer application.

The hardened samples were left for 14 days in closed plastic boxes to prevent quick water evaporation from the geopolymer surface and for the next 7 days uncovered in a laboratory (at normal temperature and pressure). Polished sections of the samples were prepared. They were observed by optic microscopy and subsequently studied and analyzed by SEM/EDAX methods.

The main reason for dousing is to remove the powder from the surface and to eliminate fast desiccation of alkaline solution from the geopolymer mixture. The geopolymer mixtures applied to the concrete surface are summarized in Table 1. In all cases, a claybased geopolymer was used as a matrix. The content of additives/fillers was selected based on previous experience $[11,15,23,26,27]$ and with respect to the viscosity and workability of the geopolymer mixture.

\section{Materials}

The materials employed in the experiments are mentioned below. The chemical compositions are shown in Table 2 (L.O.I. - loss on ignition).

- The clay material L05, used for geopolymer-matrix preparation, has been supplied by ČLUZ (Nové Strašecí, Czech Republic). The parameters of the product (the chemical composition, particle size, etc.) are guaranteed by the producer (a particle size of $\left.0-25 \mu \mathrm{m}, \mathrm{d}_{50}=3 \mu \mathrm{m}\right)$. Mineralogical composition of clay material is following: the majority of roentgenamorphous phase, quartz $\left(\mathrm{SiO}_{2}\right)$, anatase $\left(\mathrm{TiO}_{2}\right)$, minor amount of muscovite $\left(\mathrm{KAl}_{2}\left(\mathrm{Si}_{3} \mathrm{Al}\right) \mathrm{O}_{10}(\mathrm{OH})_{2}\right)$ and hematite $\left(\mathrm{Fe}_{2} \mathrm{O}_{3}\right)$ in traces.

- Micro-milled quartz sand (brand name: ST 2) and quartz sand (brand name: ST 10/40) have been supplied by Sklopísek Střeleč, a.s. (Střeleč, Czech Republic). The granularity ranges of ST 2 and ST 10/40 are $0-0.090 \mathrm{~mm}\left(\mathrm{~d}_{50}=27 \mu \mathrm{m}\right)$ and $1.00-4.00 \mathrm{~mm}\left(\mathrm{~d}_{50}=\right.$ $=1.99 \mathrm{~mm})$, respectively.

- The blast-furnace slag originating from the $19^{\text {th }}$-century iron production was applied into the GbM according to previous work $[11,23,26,27]$. The uniformity and chemical stability of the slag stored in damps close to the town of Kladno (Czech Republic) have 
Perná I., Hanzliček T., Žaloudková M.

Table 2. The chemical compositions of the materials used (the main oxides in wt. \%).

\begin{tabular}{lccccccrr}
\hline Material/Oxide & $\mathrm{SiO}_{2}$ & $\mathrm{Al}_{2} \mathrm{O}_{3}$ & $\mathrm{CaO}$ & $\mathrm{MgO}$ & $\mathrm{Fe}_{2} \mathrm{O}_{3}$ & $\mathrm{~K}_{2} \mathrm{O}$ & $\mathrm{SO}_{3}$ & L.O.I. \\
\hline L-05 & 50.28 & 41.99 & 0.14 & $<0.02$ & 1.03 & 0.59 & 0.21 & 3.65 \\
Blast-furnace slag & 22.38 & 8.09 & 37.44 & 3.51 & 2.31 & 1.26 & 7.46 & 14.70 \\
Shale clay & 54.69 & 28.63 & 0.59 & 0.62 & 7.07 & 3.72 & 0.73 & 1.60 \\
Quartz sand ST 2 & 98.97 & 0.45 & $<0.001$ & 0.08 & 0.04 & $<0.001$ & $<0.001$ & 0.1 \\
Quartz sand ST 10/40 & 98.43 & 0.41 & $<0.001$ & 0.09 & 0.04 & $<0.001$ & $<0.001$ & 0.1 \\
\hline
\end{tabular}

been demonstrated by previous sampling and testing (a particle size of $0-180 \mu \mathrm{m}, \mathrm{d}_{50}=32 \mu \mathrm{m}$ ). The XRD analyses have shown the major content of gehlenite $\mathrm{Ca}_{2} \cdot\left(\mathrm{Mg}_{0.25} \mathrm{Al0.75}\right) \cdot\left(\mathrm{Si}_{1.25} \mathrm{Al}_{0.75} \mathrm{O}_{7}\right)$, the minority of calcite $\left(\mathrm{CaCO}_{3}\right)$, merwinite $\left(\mathrm{Ca}_{3} \mathrm{Mg}(\mathrm{SiO} 4)_{2}\right)$, ettringite $\left(\mathrm{Ca}_{6} \mathrm{Al}_{2}\left(\mathrm{SO}_{4}\right)_{3}(\mathrm{OH})_{12} \cdot 25 \mathrm{H}_{2} \mathrm{O}\right)$ and quartz $\left(\mathrm{SiO}_{2}\right)$ and trace amounts of gypsum $\left(\mathrm{CaSO}_{4} \cdot 2 \mathrm{H}_{2} \mathrm{O}\right)$, vaterite $\left(\mathrm{CaCO}_{3}\right)$, thaumasite $\left(\mathrm{Ca}_{3} \mathrm{Si}(\mathrm{OH})_{6}\left(\mathrm{CO}_{3}\right)\left(\mathrm{SO}_{4}\right) \cdot 12 \mathrm{H}_{2} \mathrm{O}\right)$, hematite $\left(\mathrm{Fe}_{2} \mathrm{O}_{3}\right)$, and tridymite $\left(\mathrm{SiO}_{2}\right)$. These results have clarified high L.O.I value (Table 2 ) caused by the presence of carbonates, sulfates and hydrates.

- The shale, overburden extracted during coal mining, originates from the Zbůch region, Czech Republic (a particle size of $0-280 \mu \mathrm{m}, \mathrm{d}_{50}=13 \mu \mathrm{m}$ ). The XRD results have proved the presence of quartz $\left(\mathrm{SiO}_{2}\right)$ as a major phase, magnetite $\left(\mathrm{Fe}_{2} \mathrm{O}_{3}\right)$, cristobalite $\left(\mathrm{SiO}_{2}\right)$ and mullite $\left(3 \mathrm{Al}_{2} \mathrm{O}_{3} \cdot 2 \mathrm{SiO}_{2}\right)$ as minor phases and a certain proportion of the roentgen-amorphous phase and hematite $\left(\mathrm{Fe}_{2} \mathrm{O}_{3}\right)$.

\section{Methods}

Non-destructive X-ray fluorescence (XRF) spectrometry (Spectro IQ, Kleve, Germany) was used, with the target material being palladium and the target angle from the central ray being $90^{\circ}$. The focal point was a $1 \times 1 \mathrm{~mm}$ square, with the maximum anode dissipation of 50 watts and $10 \mathrm{cfm}$ forced-air cooling. The instrument was equipped with a HOPG Barkla crystal. The tested samples were prepared by the pressed-pellet method: $4.0 \mathrm{~g}$ of the material (a particle size of $15-20 \mu \mathrm{m}$ ) were mixed for 10 minutes with $0.9 \mathrm{~g}$ of a binding additive (HWC Hoechst wax, Germany). The pressing power was $80 \mathrm{kN}$. All of the results were automatically recalculated to the oxide form.

$\mathrm{X}$-ray diffraction patterns were recorded on a Bruker D8 Advance $\mathrm{X}$-ray diffractometer using $\mathrm{Cu} \mathrm{K} \alpha$ radiation and a Lynx Exe XE detector. Recordings were made with an automatic divergence iris diaphragm (ADS, $10 \mathrm{~mm}$ ) in the range of $4-80^{\circ}$, in steps of $0.015^{\circ}$ and $0.8 \mathrm{sec}$ reading time per step. The records were qualitatively evaluated using Diffrac EVA 2015 software, HighScore 3.0 and PDF 2 (2002).

Image analyses of polished cross sections were performed by a Nikon Optishot 100S (Nikon) microscope supplemented with a ProgRes (JENOPTIK) color digital microscope camera and an AR system (Nikon) NISelement.
The sample surface was studied by Scanning Electronic Microscopy (SEM) on a Quanta 450 scanning electron microscope (FEI, USA). The high-vacuum mode was used, and images were taken on an EverhartThornley detector (ETD) in the secondary electron mode. On the same microscope, the X-ray microanalysis of chemical elements was performed with an energy dispersive spectrometer (EDS) with a silicon drift $\mathrm{Si}(\mathrm{Li})$ Apollo detector (SDD) with a FET preamplifier. The data acquisition was done using the EDAX TSL OIM software with ZAF corrections.

\section{RESULTS AND DISCUSSION}

The hardened samples were cut with a diamond wheel saw, which was a preparative step before the polished sections were studied by an optic microscope followed by SEM/EDAX analyses.

The fast diamond wheel rotation cracked both sides of the materials and the GbM (layer thickness of 3 - $4 \mathrm{~mm}$ ) was chipped off, especially in the case of samples 1, 1M (pure matrix), 2 and $2 \mathrm{M}$ (41 wt. \% blastfurnace slag). For this reason, these samples $(1,1 \mathrm{M}$, 2 and $2 \mathrm{M}$ ) were excluded from subsequent microscopic analyses. Photographs of the samples selected for further microscopic examination are summarized in Figure 1. In all images, the geopolymer coating layer is in the upper part of the figure and the concrete at the bottom.

Samples 4 and 4M are brownish due to the shale clay used, which contains a higher amount of iron oxide (7.07 wt. \%). The rest of the samples have a pinkish color, ranging from a light color for geopolymer with micro-milled sand (samples 3 and $3 \mathrm{M}$ ) to a darker one for a matrix containing blast-furnace slag (samples 7 and $7 \mathrm{M}$ ). The structure of the geopolymer matrix in samples of 5 and $5 \mathrm{M}$ is dominated by quartz sand, whose size corresponds to the size of the sand used in the production of concrete. This sand is also evident in samples 6 and $6 \mathrm{M}$, where it is combined with micro-milled sand. The last GbM combinations applied (7 and 7M) have resulted from previous experience $[11,23]$. The addition of micro-milled sand has improved the viscosity of the mixture. The blast-furnace slag accelerates setting and hardening. Moreover, it improves the surface hardening and resistance. For these reasons, it is often used in laboratories all over the world [7-9, 23]. 

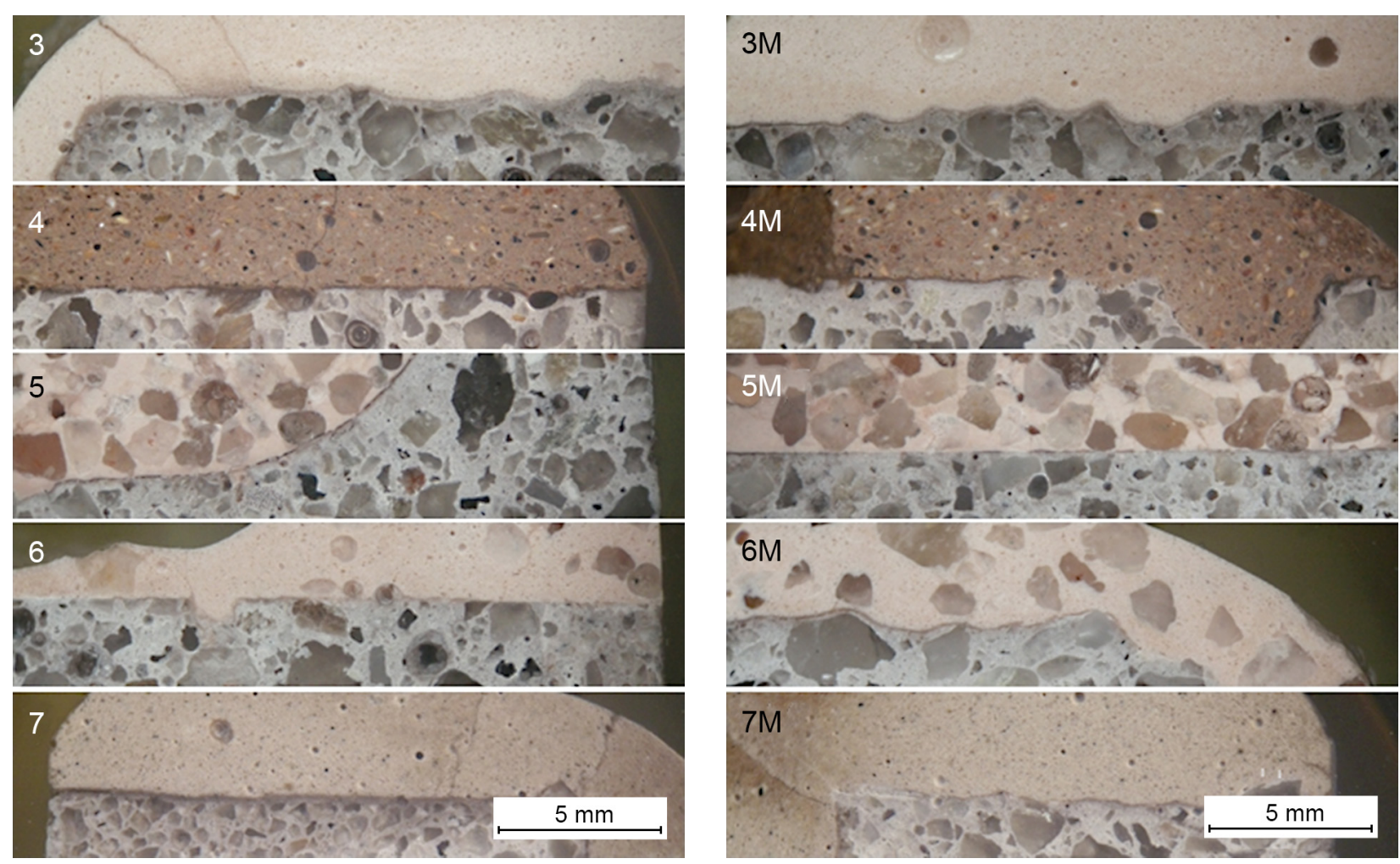

Figure 1. Photographs of the samples.
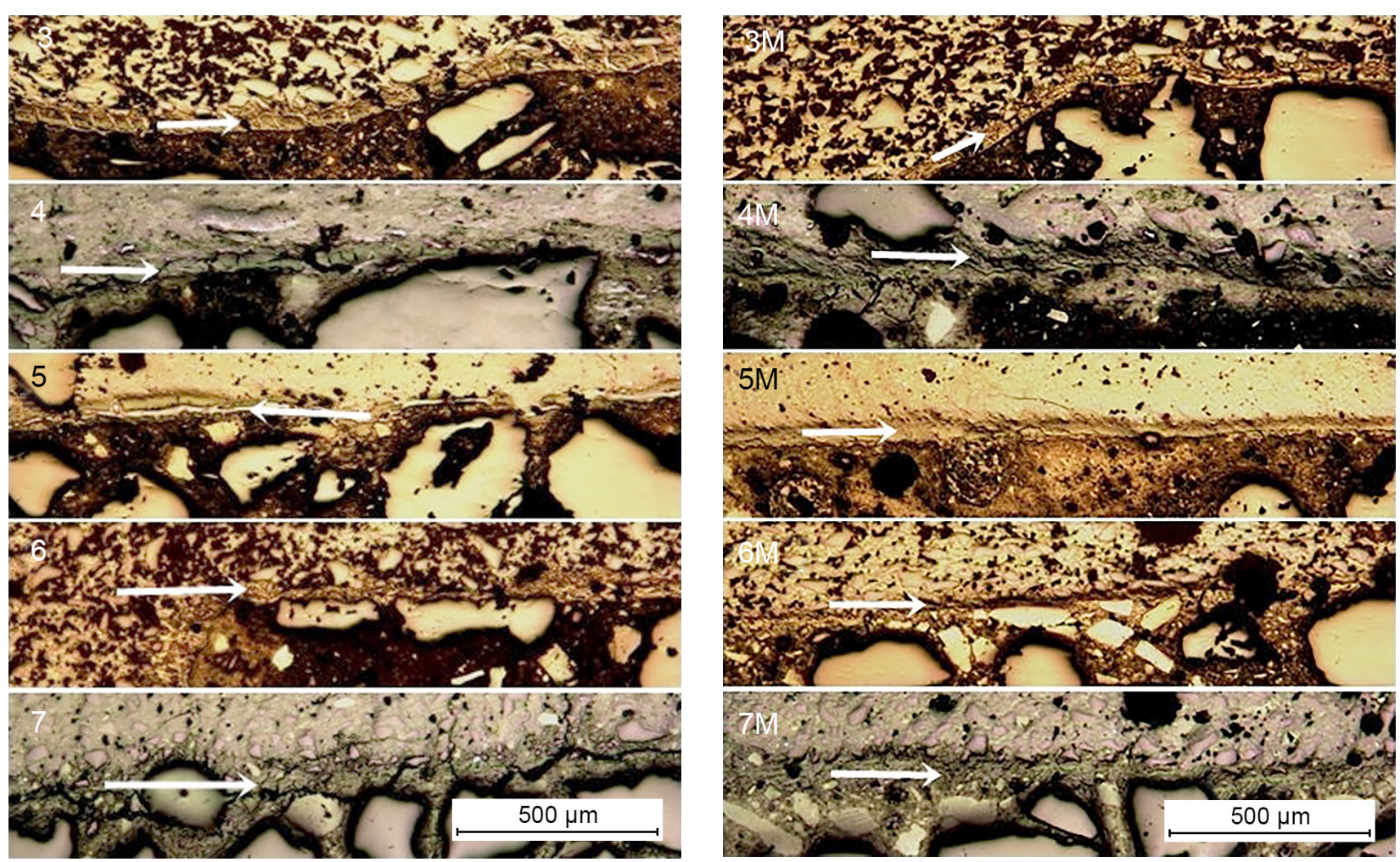

Figure 2. An overview of the polished cross sections investigated (interlayers marked by arrows). 
All samples have a visible interlayer at the interface between the concrete and the geopolymer coating materials, which will be the subject of further investigation. The cutting immediately divided the samples into two different groups. The majority of the chosen combinations did not withstand the sawing of a thin section $(3 \mathrm{~mm})$ in the cases when the GbM mixture had been applied to a dry concrete surface. The explication is in the fast suction of the GbM liquid before the chained structure is created. The porous structure draws off the liquid from the GbM, which leads to the formation of visible hair-like fissures.

The polished cross sections of the samples documented in Figure 1 were further examined under a digital microscope. The overview is presented in Figure 2.

The higher resolution has revealed that the interlayers (marked by arrows), which appeared to be compact in the photos, are cracked - especially for dry-concrete applications $(3,4,5,6$ and 7). Fine cracks are also visible in sample $4 \mathrm{M}$. However, the interlayers of samples $3 \mathrm{M}, 5 \mathrm{M}, 6 \mathrm{M}$ and $7 \mathrm{M}$ are compact and very well interconnected with both the concrete and the geopolymer layer.

Detailed SEM/EDAX studies have only been performed on the $3 \mathrm{M}$ sample, containing the standard material (micro-milled quartz sand). The main reasons are as follows: (i) Quartz sand is the most widely used additive in the preparation of geopolymer materials, which will make it possible to compare the obtained results with the international ones; (ii) the large quartz grains in $5 \mathrm{M}$ and $6 \mathrm{M}$ samples can misrepresent the EDAX measurement results; (iii) the study of the interlayer and the potential migration of ions from the concrete to the geopolymer can be affected by calcium ions contained in the slag (7M). Moreover, the blast-furnace slag (Kladno, Central Bohemian region) and naturally burned slate clay (heaped coal-mining waste) may be considered as specific regional materials from the Czech Republic, which would complicate the comparison with other international research.

Figure 3 presents a concrete surface with an applied geopolymer/sand admixture $(3 \mathrm{M})$. There are two very different areas and a compact line of an intermediate layer. The upper part is the GbM with visible small sand grains and the bottom part is concrete. The observed fine cracks in the GbM are the result of fast dewatering (the upper right-hand corner). The most important part is an interlayer (area 3), discernible in the middle of the picture between the two materials. It is possible to observe the segregated (light in color) geopolymer matrix. All the cracks observed at the joint may have a mechanical cause - the cutting of very thin sections has slightly damaged the transition zone, but the stability of the joined materials is good enough to hold both materials together. The chemical compositions of the different areas selected have been determined by EDAX and are summarized in Table 3.

The complete overview (1) is the average composition of the whole sample studied. Even the area (2) is directly connected to the lower intermediate layer (3); their chemical compositions are very different, especially in $\mathrm{Al}$ and $\mathrm{Ca}$ contents. The intermediate (3) is a layer containing calcium and its composition is similar to that of the concrete studied separately in the area (5). The calcium content is lower in the areas (2) and (4) the GbM and chemical compositions of both areas are similar.

The confirmation of the ions migration on the surface could be demonstrated by the lowering ratio $\mathrm{CaO} / \mathrm{SiO}_{2}$ at area (5) and (3) calculated as 1.378 and 1.08, respectively. However more important is the potassium ion migration in opposite site when ratio of $\mathrm{K}_{2} \mathrm{O} / \mathrm{SiO}_{2}$ shows values 0.35 and 0.28 for the area (3) and concrete area (5), respectively. Complementing ratio $\mathrm{Al}_{2} \mathrm{O}_{3} / \mathrm{SiO}_{2}$ in

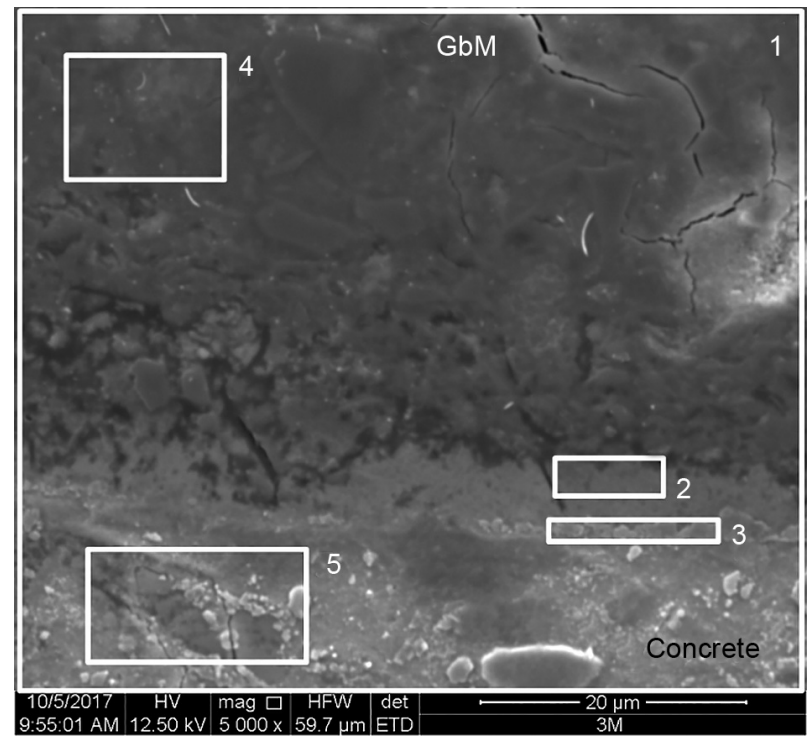

Figure 3. SEM analysis of the $3 \mathrm{M}$ sample, magnitude: $5000 \times$ ( 1 - the whole surface, 2 - gray layer, 3 - interlayer, $4-\mathrm{GbM}$, 5 - concrete).

Table 3. The EDAX results of the different areas of the cross section studied.

\begin{tabular}{ccrrrrrr}
\hline Area & $\mathrm{O}$ & $\mathrm{Al}$ & $\mathrm{Si}$ & $\mathrm{K}$ & $\mathrm{Ca}$ & $\mathrm{Na}$ & $\mathrm{Mg}$ \\
\hline 1 & 30.63 & 10.10 & 31.63 & 12.54 & 15.10 & 0.00 & 0.00 \\
2 & 22.43 & 11.87 & 37.43 & 16.04 & 4.88 & 0.22 & 0.13 \\
3 & 32.43 & 5.90 & 18.59 & 11.67 & 30.79 & 0.34 & 0.29 \\
4 & 29.31 & 13.43 & 36.71 & 15.45 & 5.10 & 0.00 & 0.00 \\
5 & 33.16 & 5.22 & 16.79 & 8.48 & 35.42 & 0.38 & 0.56 \\
\hline
\end{tabular}


both studied areas is similar. The minimal difference between values of areas (3) and (5) supports the idea of alumino-silicate joints which are hardly movable due to its dimensions.

A comparison of these results in terms of the properties of both materials reveals that even the surface of the concrete is solid, and the interchanges of ions are possible when alkali aqueous solutions are applied to it. On the other hand, calcium affects the bonding layer on the side of a geopolymer composite. A precondition for the formatted bonding layer is the moistening of the concrete body. The dousing prevents the fast dewatering of the GbM through the porous concrete surface and secondly facilitates ion interchange on the concrete-geopolymer boundary. It is interesting to follow the content of aluminum ions, which are in the areas (4) and (2) close to their calculated value rate to silicon ( $\mathrm{GbM}$ matrix $\left.\mathrm{SiO}_{2}: \mathrm{Al}_{2} \mathrm{O}_{3}=3.31: 1\right)$. The real state in the area (4) is $2.73: 1$ and the area (2) shows the molar rate of $3.15: 1$, but in neither of the high-calcium zones (3) and (5) does the aluminum content exceed 6 wt. $\%$.

In the area (2), the equilibrium to the four-fold coordinated aluminum ion is predominantly achieved through potassium ions, with the minimal influence of calcium ions. In the high-calcium zone (3), on the other hand, the calcium ions are blocked. The small amount of calcium ions (4.88 wt. \%) in the upper zone (2) is enough to lower considerably the effect of environmental influences on concrete bodies, which is confirmed by the analyses of the zone (4) - GbM.

The resulting chemical composition of transition zones acquired by EDAX confirms that the GbM practically locks the calcium ions and then prevents the negative environmental influences on the concrete surface. The coating could reduce the formation of $\mathrm{CaCO}_{3}$ or $\mathrm{CaSO}_{4}$ (in all modifications) from the easily accessible superficial $\mathrm{Ca}^{2+}$. The elimination of the effects of humidity and temperature changes could effectively stop the degradation of concrete constructions, especially in coastal zones.

The application to a wet concrete surface was used for the final studies confirming the importance of water as the transport medium for electrical balance between the negative charge of alumina ions in four-fold coordination and the positive charge of alkalis. When water is sucked rapidly, which is the case of a dry surface, the forming geopolymer layer does not adhere perfectly to the surface, the oscillation of the fast diamond wheel rotation cracks both sides of the materials, and the GbM (layer thickness of 3-4 mm) is chipped off.

\section{CONCLUSION}

This study has investigated the application of the coating layers of a geopolymer-based material $\mathrm{GbM}$ ) to hardened concrete. GbM of seven different compositions has been applied to a dry or wetted concrete surface. The application to the dry surface has caused fast desiccation of the liquid phase from the GbM, which has resulted in lower resistance to the vibrations of the cutting saw, causing fissures and cracks visible under the optical microscope.

Wetting the concrete surface before the application has improved the formation of a compact interlayer, and SEM analyses have revealed chemical linkage between the materials discussed. It has been found that the application of GbM to a wet concrete surface considerably lowers the amount of calcium ions in the coating layer. As mentioned above, the "free $\mathrm{Ca}^{2+}$ " ions in hydrated form are the most attackable components on the concrete surface. The GbM coating layer could block the incorporation of these ions into the formed $3 \mathrm{D}$ net and thus protect the concrete surface. The results of EDAX analyzes have confirmed that there is no migration of calcium ions into the geopolymer layer but the interlayer is formed by a new matter containing $\mathrm{Ca}^{2+}$ and $\mathrm{K}^{+}$ions, originating from the concrete and geopolymer, respectively.

The concept of protective coating layers is to lock the calcium ions and keep them away from environmental influences. The possibility of material layering, verified by previous experiments [15], offers a new way of repairing damaged concrete structures, where GbM will serve as a "protective layer".

\section{Acknowledgments}

This work was carried out thanks to the support of the long-term project for the conceptual development of the research organization No. 67985891 and the Strategy AV21, activity of the Czech Academy of Sciences, the research program VP05 - New Materials Based on Metals, Ceramics and Composites. The authors acknowledge Martina Křžzová and Nikoleta Čímová for their assistance with image analyses.

\section{REFERENCES}

1. Elnaggar E. M., Elsokkary T. M., Shohide M.A., El-Sabbagh B. A., Abdel-Gawwad H. A. (2019): Surface protection of concrete by new protective coating. Construction and Building Materials, 220, 245-252. Doi: 10.1016/j.conbuildmat.2019.06.026

2- Zhang B., Tan H., Shen W., Xu G., Ma B., Ji X. (2018): Nano-silica and silica fume modified cement mortar used as Surface Protection Material to enhance the impermeability. Cement and Concrete Composites, 92, 7-17. Doi: 10.1016/j. cemconcomp.2018.05.012.

3. Iqbal N., Sharma P. K., Kumar D., Roy P. K. (2018): Protective polyurea coatings for enhanced blast survivability of concrete. Construction and Building Materials, 175, 682-690. Doi: 10.1016/j.conbuildmat.2018.04.204 
4. James A., Bazarchi E., Chiniforush A. A., Aghdam P. P., Hosseini M. R., Akbarnezhad A., Martek I., Ghodoosi, F. (2019): Rebar corrosion detection, protection, and rehabilitation of reinforced concrete structures in coastal environments: A review. Construction and Building Materials, 224, 1026-1039. Doi: 10.1016/j.conbuildmat.2019.07.250

5. Bye G. C. (1999). Portland cement: composition, production and properties. $2^{\text {nd }}$ ed. Thomas Telford, London

6. Hewlett P., Liska M. (2019). Lea's chemistry of cement and concrete. $5^{\text {th }}$ ed. Butterworth-Heinemann.

7. Zhang Z., Yao X., Zhu H. (2010): Potential application of geopolymers as protection coatings for marine concrete: I. Basic properties. Apply Clay Science, 49, 1-6. Doi: 10.1016/j.clay.2010.01.014

8. Zhang Z., Yao X., Zhu H. (2010): Potential application of geopolymers as protection coatings for marine concrete: II. Microstructure and anticorrosion mechanism. Apply Clay Science, 49, 7-12. Doi:10.1016/j.clay.2010.04.024

9. Zhang Z., Yao X., Wang H. (2012): Potential application of geopolymers as protection coatings for marine concrete III. Field experiment. Apply Clay Science, 67, 57-60. Doi:10.1016/j.clay.2012.05.008

10. Roghanian N., Banthia, N. (2019): Development of a sustainable coating and repair material to prevent bio-corrosion in concrete sewer and waste-water pipes. Cement and Concrete Composites, 100, 99-107. Doi: 10.1016/j. cemconcomp.2019.03.026

11. Perná I., Hanzlíček T., Boura P., Lučaník A. (2017): Application of a clay-slag geopolymer matrix for repairing damaged concrete: Laboratory and industrial-scale experiments. Materials Testing, 59(10), 929-937. Doi: 10.3139/ 120.111090

12. Biondi L., Perry M., Vlachakis C., Wu Z., Hamilton A., McAlorum J. (2019): Ambient cured fly ash geopolymer coatings for concrete. Materials, 12(6), 923. Doi: 10.3390/ ma12060923

13. Wang Y., Zhao J. (2019): Facile preparation of slag or fly ash geopolymer composite coatings with flame resistance. Construction and Building Materials, 203, 655-661. Doi: 10.1016/j.conbuildmat.2019.01.097

14. Sicakova A. (2018): The Influence of Different Pre-Treat'ments of Concrete Surface on the Bond Strength of Geopolymer-Type Coating Layer. Sustainability, 10(11), 4053. Doi: 10.3390/su10114053

15. Hanzlíček T., Steinerová M., Straka P., Perná I., Siegl P., Švarcová T. (2009): Reinforcement of the terracotta sculpture by geopolymer composite. Materials \& Design, 30(8), 3229-3234. Doi:10.1016/j.matdes.2008.12.015

16. Liew Y. M., Heah C. Y., Kamarudin H. (2016): Structure and properties of clay-based geopolymer cements: A review. Progress in Materials Science, 83, 595-629. Doi:10.1016/j. pmatsci.2016.08.002
17. Reddy M. S., Dinakar P., Rao B. H. (2016): A review of the influence of source material's oxide composition on the compressive strength of geopolymer concrete. Microporous and Mesoporous Materials, 234, 12-23. Doi:10.1016/j. micromeso.2016.07.005.

18. Davidovits J. (2015). Geopolymer Chemistry and Applications, $4^{\text {th }}$ ed. Geopolymer Institute, France

19. Provis J. L. (2018): Alkali-activated materials. Cement and Concrete Research, 114, 40-48. Doi:10.1016/j.cemconres. 2017.02.009.

20. Ng C., Alengaram U. J., Wong L. S., Mo K. H., Jumaat M. Z., Ramesh S. (2018): A review on microstructural study and compressive strength of geopolymer mortar, paste and concrete. Construction and Building Materials, 186, 550-576. Doi: 10.1016/j.conbuildmat.2018.07.075.

21. Shubbar A. A., Sadique M., Kot P., Atherton W. (2019): Future of clay-based construction materials - A review. Construction and Building Materials, 210, 172-187. doi: 10.1016/j.conbuildmat.2019.03.206

22. Zhang P., Zheng Y., Wang K., Zhang J. (2018): A review on properties of fresh and hardened geopolymer mortar. Composites Part B: Engineering, 152, 79-95. Doi: 10.1016/ j.compositesb.2018.06.031

23. Perná I., Hanzlíček T. (2016): The setting time of a clayslag geopolymer matrix: the influence of blast-furnaceslag addition and the mixing method. Journal of Cleaner Production, 112, 1150-1155. Doi:10.1016/j.jclepro.2015.05. 069.

24. Neupane K., Chalmers D., Kidd P. (2018): High-strength geopolymer concrete-properties, advantages and challenges. Advances in Materials, 7(2), 15-25. Doi:10.11648/j. am.20180702.11

25. Colangelo F., Roviello G., Ricciotti L., Ferrándiz-Mas V., Messina F., Ferone C., Tarralo O., Cioffi R., Cheeseman C. R. (2018): Mechanical and thermal properties of lightweight geopolymer composites. Cement and Concrete Composites, 86, (2018) 266-272. Doi: 10.1016/j.cemconcomp. 2017.11.016.

26. Perná I., Hanzlíček T., Boura P., Lučaník A. (2016): The manufacture of the grinding wheels based on the $\mathrm{Ca}-\mathrm{K}$ Geopolymer Matrix. Materials and Manufacturing Processes, 31(5), 667-672. Doi:10.1080/10426914.2015.1 004709.

27. Perná I., Šupová M., Hanzlíček T. (2019): A study of the Kladno blast-furnace slag: History, characterization and possible utilization. Waste forum, 1, 28-35. Available on: http://www.wasteforum.cz/cisla/WF_1_2019.pdf. 